\title{
APUNTES PARA EL ANÁLISIS DEL PATRÓN DE ASENTAMIENTO EN TULUM*
}

\author{
Ernesto Vargas P. \\ IIA-UNAM \\ Patricia Santillán S. \\ Marta Vilalta C.
}

\begin{abstract}
Para don Anastasio Dzib, ${ }^{1}$ cabo del Proyecto Tulum, quien dedicó largos años de su vida a la arqueología maya; en él queremos honrar a muchos hombres mayas que han dedicado y dedican su trabajo a la arqueología. Brindamos con esto un homenaje póstumo a Don Tasio, un gran hombre maya.
\end{abstract}

Los sitios prehispánicos de la costa oriental de Quintana Roo han tenido siempre un lugar especial en la arqueología maya; se localizan a lo largo de la costa y en las cercanías de la misma; son tan abundantes que no dejan la menor duda que la región estuvo densamente poblada en tiempos prehispánicos (Andrews 1976: 10) (Fig. 1).

Quintana Roo se puede dividir en tres provincias geográficas: la sur, cubierta por el bosque tropical y que se extiende un poco a la región central, la cual se caracteriza por el bosque tropical seco, y por último la zona del norte que se localiza en la costa oriental y toda la parte norte.

* Los levantamientos topográficos en Tulum fueron realizados por los integrantes del Proyecto Tulum; algunos trabajaron en los reconocimientos pre'sminares, otros en las descripciones, trabajos de campo y en los dibujos; Ricardo Velázquez, Patrícia Santillán, Marta Vilalta C., Yamile Lira López, Arturo Tapia, José Luis Romero, personal del Centro Regional del Sureste INAHN, de la Universidad de Veracruz y de la ENAH. 
Quintana Roo se puede dividir en tres provincias arqueológicas que son: la zona del Petén, la de Río Bec y la de la Costa Oriental. La zona del Petén es solamente periférica al gran centro maya del Petén que se encuentra en Guatemala. Sus límites norteños son Cobá y los sitios circunvecinos, por el oriente llegó hasta San Francisco o Punta Pájaros. Por el poniente tocó el Palmar, con su gran cantidad de estelas, y su influencia crece al bajar hacia Belice y Guatemala (Muller, 1956:16).

La segunda zona arqueológica es la de Río Bec. Es solamente una pequeña parte, ya que la principal se encuentra en Campeche. Está localizada en la esquina suroeste del Estado y su centro es Río Bec. Alrededor se encuentran agrupados sitios de importancia como Pasión de Cristo, Payán, Peor es Nada, Reforma, y El Palmar.

Por último, tenemos la provincia de la Costa Oriental, situada, como indica su nombre, en la parte oriental del territorio. Su influencia llegó al norte hasta Chequillá, al centro en Oxkindzonot y a la costa pasando por Tulum y hacia el sur hasta Bacalar (Muller 1956:16).

En tiempos cercanos a la Conquista la península de Yucatán quedó dividida en 19 cacicazgos de los cuales tres quedaron dentro del territorio del Estado de Quintana Roo a saber: el cacicazgo de Ecab, el de Cochuah y el de Chetumal (Fig. 2).

El cacicazgo de Ecab se extendía desde el cabo Ciatoche hasta la bahía de la Ascensión; entre sus pueblos principales se pueden citar los de Pachihohom, Cachi, Palmul, Tulum, Cehac, Mochi, Xelha y Pole. Según Oviedo, algunos de esos pueblos contaban con centenares y aun millares de casas; en cuanto a su apariencia nos dice que por lo regular, cada pueblo se componía de una plaza espaciosa y limpia de malas hierbas en la que estaban los templos, mercados, juzgados, centro de diversiones, etc. El resto de la población vivía en chozas construidas con materiales perecederos, situados en los alrededores del sitio. Fue tal la impresión que recibieron los españoles al ver el tamaño de Ecab, que le dieron el nombre de "El Gran Cairo" (Benavides 1979).

Durante esa época existió gran actividad comercial según lo narra el mismo Oviedo; en cuanto a la práctica de la agricultura hay que hacer notar que las tierras de ese cacicazgo eran poco propicias para la agricultura en gran escala.

Se sigue desconociendo buena parte del interior de la antigua provincia; los únicos trabajos que se han realizado son los de Escalona Ramos (1946), Sanders (1955, 1960), Thompson (1932), 
y en la actualidad los realizados por el Centro Regional del Sureste con los diversos proyectos en Cobá y la costa oriental.

Como se ha comprobado, el tipo de asentamiento varía según el horizonte a que se refiera. A menudo vemos en la literatura arqueológica la preocupación que existe por dar una explicación al cese de las expresiones culturales mayas; antes se veía como un fenómeno repentino y no como un proceso que traería por resultado el casi total abandono del área, y el desplazamiento de la población de una parte hacia otra. Al parecer, los efectos demográficos siempre jugaron y juegan un papel muy importante en el tipo de asentamientos, y los efectos inmediatos en la región fueron buscar formas más adecuadas de organización política, con la suficiente capacidad de planear y encontrar las soluciones más convenientes para la satisfacción de las necesidades que se iban creando (Wiley G. 1974:425).

Hablar de los primeros pobladores que ocuparon esta parte de la península de Yucatán, es todavía objeto de controversia, sin embargo, cada día, con las nuevas exploraciones realizadas en Quintana Roo se comprueba que la ocupación es anterior a la señalada por el Chilam Balam de Mani, cuando narra la ocupación de Bacalar: "Tres veintenas de años reinaron en Siyan Can (Bakhalal) y bajaron aquî" (435-495).

En la actualidad, con el aporte de nuevos datos arqueológicos se ha constatado que la región en sí fue habitada desde el Preclásico Superior por lo menos, tanto en sitios costeros como en el interior. Algunos de los sitios reportados son los siguientes: El conchero de Can Cun (Andrews 1975), Kocholnah (Mayer 1976), Playa del Carmen (Gonzáles de la Mata 1980), Xelhá (Robles 1980), Ixil y Cobá fueron posiblemente desde entonces sociedades de agricultores sedentarios y los de los sitios costeros, en cambio, fueron seguramente pescadores.

Durante el Clásico existen pocos sitios ubicados en la costa pero al parecer la mayor ocupación se da en el interior. Entre las evidencias del Clásico se encuentra la Estela 1 de Tulum que data del 564 D.C., la estela de Ichpaatum del 593 D.C., el dintel de madera de Tzibanché del 618 D.C. y los sitios con cerámica del Clásico como son Xelhá, El Meco, Akumal y Cozumel entre otros.

La mayor ocupación corresponde precisamente al Postclásico Tardío (1200-1520), estos asentamientos se encuentran a lo largo de la costa y en el interior adyacente, son tan abundantes que no dejan duda alguna que la región estuvo densamente poblada en tiempos prehispánicos. La costa central presenta un ambiente muy favorable 
para una población densa, existen abundantes y variados recursos marinos que se pueden explotar a través del año, además la proximidad a las rutas marítimas del Caribe facilita la comunicación y asegura el acceso al comercio costero de la región (Andrews 1976: 10).

Andrews nos dice que el gran número de sitios costeros del periodo Decadente sugiere un incremento demográfico de dimensiones mayores durante esa época. Es posible que haya sido el resultado de un movimiento hacia la costa, sus recursos y su comercio, en tiempos postclásicos. Sin embargo, las razones detrás de este movimiento, en el contexto de lo que sucedía en el interior de la península, es un problema sumamente interesante que requiere futuros estudios (Andrews 1976:18-19).

$\mathrm{Al}$ parecer, por los trabajos realizados, la mayor prosperidad se alcanza en los dos siglos en que según las fuentes escritas existió la liga de Mayapán (1263-1461) formada por Chichén Itzá, Uxmal y Mayapán que disputaban la hegemonía de la península. Durante esta época se desarrolló un gran número de sitios en Quintana Roo.

Sanders hacia 1955 realiza excavaciones en varios sitios de la costa oriental, entre ellos Tulum, y reconocimientos generales en el área, diferenciando 4 tipos de asentamientos:

1) Con una o más plazas flanqueadas por estructuras ceremoniales formando un núcleo; estructuras religiosas o grupos de estructuras diseminadas a una distancia del centro; y un número limitado de plataformas distribuidas en las cercanías, que pueden funcionar como casas habitacionales (este tipo es común durante el Clásico y el Postclásico Temprano).

2) Un edificio ceremonial principal con otras estructuras ceremoniales.

3) Sitios que pueden sugerir una villa rural, con unas 12 plataformas - posibles casas habitacionales- y una pequeña pirámide.

4) Sitios con un plano definido. Centro ceremonial rodeado por posibles casas habitación en lotes defendidos por muros. Este tipo puede ser semejante a una villa moderna, y quizás, posteriores a la Conquista.

En 1975 aparece la publicación de Andrews, W. y A. Andrews con el estudio sobre las ruinas de Xcaret y notas sobre sitios arqueológicos de la costa este central de la península de Yucatán, que abarca desde Playa del Carmen hasta Tulum. 
Al final del trabajo señalan la existencia de 3 tipos de sitios, diferenciándolos por su localización:

a) Sitios adentro, entre los 300 y $3000 \mathrm{mts}$. de la costa. Incluye Chakalal, Puha, Punta Chele, Saac, Akumal Xelhá y Tancah.

b) Sitios costeros en las inmediaciones de la costa o a menos de $300 \mathrm{mts}$. de ésta, incluyendo Playa del Carmen, Xcaret, Paamul y Tulum.

c) Edificios costeros aislados a lo largo de casi toda la costa, incluyendo Chakalal, Punta Chile, Xaax, Yalku, Akumal, Xelhá y Punta Tulsayab.

Este trabajo es completado con otro que realiza A. Andrews en 1982, reconociendo el área comprendida entre Tulum y Punta Allen. De este modo queda cubierta una franja de tierra de aproximadamente $3 \mathrm{kms}$. de ancho por $80 \mathrm{kms}$. de largo.

En esta área, que se ha llamado la Costa Central de Quintana Roo, se han realizado estudios de gran importancia. Baste recordar los trabajos en Xcaret (Andrews 1975), Playa del Carmen (González de Mata y Trejo Alvarado 1978), Punta Piedra (Miller 1975, Benavides 1976), Tulum (Martínez 1974, Velázquez 1975, Vargas 1981).

Se han realizado diferentes tipos de trabajos: algunos enfocados fnudamentalmente a la restauración y consolidación, otros enfocados a la arquitectura, al salvamento, al estudio de la cerámica y al patrón de asentamiento completo de sitios.

Dentro del Proyecto arqueológico de Tulum se planeó desde un principio la necesidad de conocer la totalidad del sitio tanto dentro de la muralla como fuera de ella.

\section{TULUM}

En Tulum se hicieron reconocimientos sistemáticos con el fin de conocer la distribución de su asentamiento. Hacia 1920 la Institución Carnegie de Washington realizó varias expediciones en la costa oriental y O. G. Ricketson hizo un reconocimiento para realizar los mapas de Tulum, Tancah y Xelhá.

La ciudad está limitada al oriente por los acantilados y en los otros tres lados por una ancha muralla, formando así un recinto rectangular de unos $4.00 \mathrm{mts}$. de norte a sur por $170 \mathrm{mts}$. de este a oeste (Fig. 3). 
La muralla limita al centro cívico ceremonial en sus lados norte, oeste y sur, tiene 5 entradas y de trecho en trecho existen gradas para ascender. Con la limpieza y conservación de la muralla se planteó la necesidad de conocer su función y sus relaciones con la población extramuros. También se ha obtenido información detallada para entender el carácter defensivo de ésta y para sacar algunas inferencias de tipo social.

Sobre la distribución de las edificaciones en Tulum se ha contado con una magnífica información; faltaban el estudio y la distribución de plataformas bajas y cimientos para habitación que se hacían principalmente de materiales perecederos.

La organización general de Tulum es sobre dos ejes paralelos (Andrews G. 1975) que actuarían como canalizadores del movimiento de la gente hacia puntos específicos; el más importante va de la puerta noreste a Ia suroeste y hacia la mitad conectaría perpendicularmente con una especie de plaza a través de la cual se llegaría al área central. A esta área se podría llegar como se llega hoy en día también por la puerta oeste.

El segundo va directamente de la puerta sureste al área central. Por la puerta noreste también existe otro camino que se va delimitando por la estructura 35, plataformas bajas y terrazas que durante las recientes exploraciones quedaron a la vista, al parecer se dirige hacia "el mercado", llamado así por Sanders.

Con la limpieza y exploración realizadas durante la temporada de 1981 se localizó una serie de plataformas que se alinean de tal manera que forman una tercera calle.

Alrededor de estas calles se distribuyen, por lo general, algunos edificios, plataformas bajas y/o cimientos para habitaciones de materiales perecederos.

En el interior de la muralla se encuentran los principales edificios; señalaremos algunos elementos para resaltar el contraste que existe entre el interior y el exterior y a su vez entre el lado sur y el norte.

Fundamentalmente las formas de patrones de asentamiento que se dan en Tulum son las siguientes:

1) Basamento piramidal llamado comúnmente así y orientado hacia el poniente. En la parte superior tiene un templo y se localiza al centro de Tulum, siendo El Castillo el principal (Lám. 1).

2) Construcciones con techo de mampostería.

En Tulum se dan dos tipos: 
a) Bóvedas con un solo cuerto.

b) Techos planos sostenidos con columnas y/o pilastras y varios cuartos. Ejemplos del primero son los templos de la Crestería (Fig. 4) y la Casa de las Nauyacas, y del segundo, la mayoría de los edificios del interior de la muralla.

A este tipo de construcciones se le han asignado diferentes funciones, entre ellas, habitaciones del grupo sacerdotal (Landa 1966: 28) y domicilio de las familias de la clase dominante (Morley 1947). Thompson (1959:70-72), a su vez, nos dice que eran demasiado incómodas para servir de habitación. Sanders ha propuesto que cuando existen varias plataformas juntas, cada vestigio no se puede ver como una casa habitación, sino que, se debería de pensar en la función que tenía cada una de ellas ya que puede ser diferente y per. tenecer a una sola familia.

Ejemplo de este último caso podría ser el conjunto de la Calle Principal en donde tenemos un edificio con techo de mampostería, al frente y a su izquierda existen plataformas de diferente altura y con detalles arquitectónicos variados (Lám. 2).

3) Construcciones con techo perecedero.

En el centro principal de Tulum no hemos encontrado ningún resto de casas ovaladas; en las afueras de la muralla sí se excavaron algunos ejemplos. Casi todos los cimientos son rectangulares (Lám. $3)$.

Con las excavaciones realizadas pudimos comprobar cómo han evolucionado las casas habitación en Tulum; desde una simple hilada de piedras a plataformas de diferentes alturas, a las que se agregan elementos con escaleras, alfardas con dados, muros en forma de talud con cornisa, altar central, divisiones internas, muros de mampostería, etc.; un estudio exhaustivo sobre las casas habitación en Tulum, formará parte de una tesis (Lám. 4).

4) Plataformas (Garza y Kurjack 1980:45).

Son el elemento constructivo más característico de los asentamientos prehispánicos de Yucatán y parecen responder a varios requerimientos:

a). es claramente un aspecto funcional, debido a la escasez del suelo; las plataformas eran empleadas para enterrar los postes que sostenían las casas.

b) las plataformas pueden mostrar el poder del grupo social que las ocupó. El volumen de material acarreado y el acabado son índices seguros del número de horas/hombre empleados en la construcción. 
La cantidad y calidad de los materiales varían en muchas ocasiones; las dimensiones y las alturas fluctúan y son factores de gran importancia en el análisis de un sitio (Lám. 5).

5) Caminos o calles internas.

Los caminos proporcionan unidad a la ciudad y pudieron funcionar como canalizadores del movimiento de la gente hacia puntos específicos.

Las calzadas son una evidencia directa de la fuerte interacción entre la gente que vivían en el sitio, y a su vez sugiere un control (Kurjack y Andrews V. 1976).

Al comenzar a estudiar los caminos (sacbés) observamos su variedad, lo cual implicaba diferentes distribuciones, características propias, funciones, etc. Es por esto que decidimos empezar por diferenciarlos en nuestro reconocimiento.

Adentro del sitio, como dijimos, se forman los ejes principales alrededor de los caminos; formándolos, están las plataformas y edificios, y señalando estos caminos las cinco entradas en la muralla (ver Fig. 3).

Afuera de la muralla los caminos se distribuyen paralelamente a la costa y al manglar; de cada puerta sale un camino, aunque en el lado sur se dan algunas variantes. En una fotografía aérea antigua todavía se puede ver una especie de camino que llegaba a la puerta central; desgraciadamente quedó totalmente destruido por la carretera de acceso a las ruinas y una ampliación para llegar al aeropuerto.

En Tulum existen varios tipos de caminos, diferenciándose claramente de los sacbés característicos del Clásico en la península de Yucatán.

a) Caminos formados por plataformas; este caso se da en el interior del sitio y en el lado sur, entre las dos murallas, en la puerta sureste (Lám. 6).

b) Caminos formados por dos andadores; los andadores son muros de piedra de aproximadamente $1 \mathrm{mt}$. de altura por $0.50 \mathrm{mt}$. de ancho en donde se podía caminar, existen fuera de la muralla en el lado norte. En el lado sur parte de este camino fue destruido, seguramente, por la carretera que va a Boca Paila mientras que en el lado norte está totalmente claro; sale de la puerta noroeste y se dirige hacia Tancah; como a los $450 \mathrm{mts}$. tiene una bifurcación que se dirige hacia el manglar y a éste llegan muchas albarradas y andadores, que a su vez se comunican con la costa y sirven para delimitar 
espacios en donde se puede encontrar gran cantidad de restos habitacionales (Fig. 5).

c) Andadores; caminos que comunican lugares más cercanos, y sirven a su vez para dividir áreas. Son muros de piedra de aproximadamente $1 \mathrm{mt}$. de altura por $0.75 \mathrm{mt}$. de ancho; tentativamente se les ha dado esa doble función; son muy abundantes en el lado sur y en el norte, además su localización es muy característica porque comunica lugares en donde se encuentra un mayor número de restos arqueológicos o existe una construcción con techo de mampostería, como son los casos de La Crestería y de La Casa de las Nauyacas (Fig| 6).

d) Caminos formados por hiladas de piedra (albarradas) que delimitan un espacio de aproximadamente $5 \mathrm{mts}$. de ancho. Ejemplos de este tipo de caminos se dan en el lado norte, uno reportado por L. Martỉnez y levantado durante nuestros trabajos de topografía y otro que llega a la puerta noreste; este camino se localiza a la orilla de la costa, ha sido bastante destruido pero en otras partes se ha conservado muy bien porque ha sido protegido por un tipo de vegetación que no permite ver absolutamente nada; fue localizado gracias a una limpieza que hicimos con otros fines. Este camino, como dijimos, sale de la puerta noreste y se dirige cerca de la costa hacia Tancah, llega claramente a los templos costeros de las Nauyacas y de allí hacia el templo de la Crestería, y de ésta hacia el norte, teniendo algunas variantes por la topografía.

\section{6) Albarradas.}

En el interior de Tulum no se da este tipo de muros de piedra, mientras que en los lados norte y sur es lo característico. Es interesante señalar que este tipo de muros y albarradas se encuentran en todas partes de la península. Bullard (1952) los encontró en Mayapán; Vlcek et al. (1978), realizó el levantamiento topográfico de un área de 500 por $250 \mathrm{mts}$. en Chunchucmil. Baker (1976) en un pequeño sitio al norte de Cuca muestra estos muros que dice pueden considerarse como rurales, pues están fuera del asentamiento mayor. En Quintana Roo ya son muy conocidos todos estos tipos de albarradas, baste citar Cobá, Xelhá, Tancah, San Gervasio, Punta Piedra, Tulum, etc.

En términos generales las albarradas pueden ser de una o varias hiladas de piedras sobrepuestas, la altura varía desde los 20 ó 30 cms. hasta el metro; y las áreas que delimitan son de planta irregular y de dimensiones muy variadas. En cuanto al número de platafor- 
mas, es también muy variado; pueden ser muy pequeñas desde un metro por dos, hasta de 20 por 30 metros de lado. En algunas de estas áreas no hemos encontrado ningún resto arqueológico, mientras que en otros hemos registrado hasta 90 .

Los muros de delimitación de propiedad debieron jugar las mismas funciones que las albarradas de hoy en día de Yucatán, es decir, marcar las orillas de la propiedad y asegurar un espacio para efectuar diversas actividades domésticas (Garza y Kurjack 1980:54).

\section{7) La muralla.}

En Tulum existen tres. La muralla interior que encierra los edificios principales, la muralla exterior que la delimita por tres de sus lados y lo separa de la zona habitacional extramuros y la muralla que se localiza en el lado sur, sale de la esquina suroeste y abarca una sección importante, siendo además ésta muy parecida a la interior (Lám. 7).

Las fortificaciones son pues un elemento importante en la defensa, ya que tienen varias finalidades: prevenir sorpresas, proteger a los que combaten, brindar seguridad a una población que vivía en las afueras de la muralla y facilitar las maniobras de las tropas que peleaban extramuros.

Algunos investigadores no ven muy clara la función defensiva de la muralla, dicen por ejemplo que la muralla termina un poco antes de llegar al acantilado, facilitando a posibles ataques el paso por ambos flancos, hacia el interior de la ciudad. También arguyen que la muralla es muy maciza, pero no es demasiado alta y es posible trepar por ella sin mucha dificultad.

Igual que muchos otros sitios. Tulum tiene una segunda muralla, más pequeña, pero circunda un espacio rectangular; posiblemente en el caso de esta segunda muralla no tiene ningún sentido militar, sino sea más bien un recinto protegido en donde se limitaría la entrada a la gente común; con las exploraciones que hemos realizado puede constatarse la construcción de ciertas paredes para cerrar los espacios libres, mientras que la muralla exterior seguramente tuvo la doble finalidad, una eminentemente defensiva y otra para el control de la gente que entraba a la ciudad amurallada de Tulum, pues a cada una de las puertas de la muralla llegaba un sacbé; y existía además un reforzamiento de vigilancia ya que en el lado norte en la primera puerta había un pequeño cuarto en donde al parecer había guardias como vigilantes; en la segunda puerta, fuera de la muralla había dos grandes plataformas situadas a la entrada 
y sobre la muralla una especie de parapeto que protegía a los vigilantes.

\section{LADO SUR DE TULUM}

Investigadores del Centro Regional del Sureste del INAH en 1974 y 1975 realizaron trabajos intensivos en el sitio y reconocimientos en las afueras del mismo. Lourdes Martínez G. (1974) nos dice:

La zona arqueológica de Tulum no tiene sus límites en la gran muralla. Durante el trabajo de campo, fueron varios los recorridos que realicé fuera de la gran muralla, con el guardián Ambrosio Camal Cupul, encontrando a nuestro paso evidencias arqueoló gicas: chultunes, pequeñas albarradas de piedra, cimientos de piedra de forma redonda - de casas - todo esto en una área de $2 \mathrm{~km}$ cuadrados aproximadamente, hacia el sur. En la esquina noroeste de la gran muralla parece que arranca un sacbé, el que se debe localizar, ya que es una de las evidencias arqueológicas más interesantes de Tulum y el dato no está asentado en libro alguno (Apéndice 1974).

Ricardo Velázquez (1975:59-60).

En tiempos en que finalizaba la temporada de trabajo se hicieron recorridos de superficie en el área sur del recinto amurallado, de-* nominándola área habitaciones sur por los restos que presentaban. Esta área no había sido investigada y por razones de tiempo no se pudo continuar trabajándola, pero se hizo lo necesario para tener una amplia idea de la importancia que encierra, para la investigación arqueológica, esta parte de la ciudad prehispánica de Tulum. El primer trabajo que se realizó después del recorrido de superficie, fue sacar una muestra del terreno con su distribución arquitectónica y los espacios que delimitaban los muros. Se hizo un plano a nivel de croquis planimétrico de una área de $100 \mathrm{mts}$. por $200 \mathrm{mts}$. ubicada en un lote de los fraccionados por la promotora Tulum...

Posteriormente esta información fue publicada por Barrera Rubio (1977:28-31) quien presenta el plano de esta muestra y dice entre otras cosas "de esta manera este sistema de muros pudo tener fines hidráulicos al coadyuvar a la formación de aguadas temporales, además de servir de vías de comunicación y como muros retentivos del suelo". 
Con anterioridad Lothrop (1924) cita tres edificios fuera de la muralla y reporta un sistema de muros que se alinean entre la costa y el manglar. Sanders (1960) nos dice que algunos de estos muros tenian fines defensivos.

Teniendo esta información de Tulum se planteó la necesidad, a instancias del arqueólogo Norberto González, de hacer el levantamiento total del sitio. Para ello nos auxiliamos de algunos planos topográficos que tenía Parques Nacionales de SAHOP, fotografía aérea que nos proporcionó la Arqla. Silvia Garza Tarazona y el Arqlo. F. Kurjack, una de 1945 y una serie que corresponde a un vuelo especial sobre la costa que abarca desde la parte sur de Tulum hasta el norte de Tancah (Detenal 14 de abril de 1979 Esc. 1-4.000).

El asentamiento de la zona habitacional del lado sur se distribuye en forma lineal delimitada al oriente por la costa y al oeste por la zona pantanosa de manglares.

En el recorrido y levantamiento topográficos de la zona habitacional sur se delimitaron calles, patios, cimientos de casas, plataformas rectangulares y ovaladas, aguadas y un cenote.

El arqueólogo Ricardo Velázquez (investigador del Centro Regional del Sureste) que con anterioridad había trabajado en Tulum, obtuvo toda la información de la distribución de los andadores, albarradas simples y dobles, de la muralla exterior y la delimitación de la zona habitacional hacia el sur. Así, él hizo la planimetría de todos estos restos arqueológicos. Una vez realizada esta labor se pasó a obtener toda la información que existía dentro de esa urdimbre de albarradas y muros. Fue una labor ardua y pesada, ya que la identificación de esos restos prehispánicos, se vuelve a veces difícil y tediosa, pues algunos de ellos no están bien definidos y otros tienen formas extrañas que en lugar de aclarar nuestra visión nos confunde. Se logró no solamente registrar toda la información existente entre esos muros, sino también se ha logrado una descrip. ción detallada de cada zona y de cada montículo.

A estos espacios que quedaban limitados por muros y/o albarradas, se les ha llamado de diferentes maneras: zonas, parcelas, áreas, etc.; por fines prácticos decidimos llamarlos zonas y enumerarlas con números romanos, mientras que a cada montículo se le dio un número arábigo. Tanto las zonas como los montículos son descritos en forma individual. La zona, en primer lugar es localizada, después se enumera la cantidad de montículos que tiene y se señalan los elementos más relevantes. A cada montículo se le da su número, 
se le localiza y se describe su forma, altura y estado de conservación en general.

La finalidad de este levantamiento es fundamentalmente conocer la distribución de la zona habitacional de Tulum y todas las implicaciones arqueológicas de un patrón de asentamiento. Pero también evitar destrucciones en el futuro, ya que desgraciadamente en años anteriores, con el auge turístico que ha tenido esa parte del territorio mexicano, ha sido afectada seriamente (Fig. 7).

Como puede observarse en el plano, la distribución de la zona habitacional del lado sur es lineal, limitada al este por la costa y al oeste por el manglar. El manglar no fue un impedimento que no se pudiera vencer, ya que por medio de caminos y andadores lograron pasar ese pantanoso manglar y llegar a tierras más firmes, en donde seguramente se encuentran más restos habitacionales y parcelas que pudieron servir de cultivo a los habitantes de Tulum; las tierras, aunque malas, son mejores que las de la costa.

Para tratar de entender mejor la zona habitacional se realizaron pozos estratigráficos, exploraciones totales de plataformas y montículos, de diferentes dimensiones y alturas.

Las principales formas de asentamiento que hemos encontrado en el lado sur son las siguientes:

1.-Construcciones con techos planos de mampostería.

2.- Plataformas hechas en piedra y materiales perecederos.

3.-Caminos formados por plataformas, caminos formados por dos andadores.

4.- Albarradas, toda la zona habitacional está formada por albarradas.

5.-Existe una muralla que delimita una área importante en el lado sur.

\section{LADO NORTE DE TULUM}

En términos generales seguimos los mismos criterios establecidos para el lado sur, diferimos únicamente en el modo de hacer el levantamiento topográfico. Tomamos como eje una brecha paralela a la playa e hicimos otras perpendiculares a ésta cada 50 mts.; quedándonos de esta manera cuadros de 50 por $50 \mathrm{mts}$. A cada $50 \mathrm{mts}$. se sacó un perfil del terreno para darnos una idea más clara sobre la topografía del lugar, además se sacaron todas las alturas para hacer 
altimetría del lugar incorporando a su vez toda la información arqueológica existente (Fig. 8).

Las descripciones y la enumeración de las zonas y montículos básicamente siguen el mismo lineamiento que en el lado sur.

Esta parte de la zona es muy interesante por varias razones; una, porque la destrucción y el saqueo es mínimo; dos, porque posiblemente la zona habitacional llega hasta Tancah; tres, porque existen elementos arqueológicos más claros, permitiéndonos todo ello contestar en jarte o plantear nuevas hipótesis sobre el desarrollo de Tulum.

Las formas de los asentamientos que hemos encontrado son:

1) Construcciones con techo de mampostería: Casa de las Nauyacas y el edificio de la Crestería.

2) Plataformas, muy abundantes de todos tamaños y alturas.

3) Pequeñas plataformas circulares, plataformas en forma de herraduras, etc.

4) Caminos:

a) formados por dos andadores y con bifurcaciones.

b) andadores.

c) caminos formados por albarradas.

5) Las albarradas son abundantísimas con la particularidad de que las mayores concentraciones se dan en las cercanías de las construcciones con techo de mampostería y cerca de la bifurcación del camino formado por el sacbé doble.

\section{COMENTARIO}

Los patrones de asentamiento han sido uno de los temas favoritos en el área maya, baste recordar el trabajo de Haviland (1966) en donde hace un análisis crítico de los trabajos efectuados hasta aquel entonces y concluye diciendo: por el momento hay que disminuir las interpretaciones reóricas acerca del patrón de asentamiento e intensificar reportes arqueológicos, especialmente de sitios habitacionales, para poder posteriormente generalizarlos, ya que las diferencias entre un sitio y otro son claras, aunque pertenezcan a una misma región.

Así pues los objetivos en el patrón de asentamiento estuvieron encaminados al estudio de las áreas fuera de la muralla para tratar de comprender las formas de patrón de asentamiento (empleados por sus habitantes), ya que es un sitio con un solo horizonte ocupa- 
cional, en donde los elementos que encontramos no reflejan transformaciones importantes durante la Época Prehispánica; y en la actualidad con la información obtenida durante nuestros reconocimientos, levantamientos topográficos y de todo el material resultado de las excavaciones, auxiliados además con la información etnológica, histórica y del medio podremos tratar de hacer una interpretación del sitio o área que hemos de investigar.

La arqueología maya por mucho tiempo se circunscribió a la localización y exploración de los conjuntos monumentales, conocidos como centros ceremoniales. Sin embargo, existe otra tendencir. de reconocer que estos sitios fueron habitados por la aristocracia en la parte central y por habitantes rurales en su periferia; a este último no se le ha prestado mucha atención, aunque existen algunos estudios sistemáticos de viviendas rurales. En Tulum, preocupados por esta última tendencia, se descubrieron y registraron cientos de montículos cercanos al centro ceremonial que contenían plataformas bajas de mampostería, cuyas dimensiones eran sensiblemente análogas a las de las chozas mayas modernas. En unos pocos casos se encontraron sobre esas plataformas construcciones de piedra, a veces incluso con bóveda.

Las plataformas se pueden hallar aisladas o bien formando pequeñas agrupaciones en torno a un patio, plaza central y rodeada por una barda. Como el tamaño variaba considerablemente de unas a otras, entre cinco y veinte metros de largo y cuatro a diez de ancho, se podía pensar en funciones específicas, lo que acentuaba las semejanzas con las unidades de habitación de los indígenas actuales. También es interesante resaltar el hecho de que ni la disposición de las viviendas ni la elección del terreno para ubicarlas son arbitrarias; se buscaron lugares próximos a fuentes de agua, en zonas altas y bien drenadas, lo cual quiere decir que no hay ruinas en los bajos que se inundan en la estación de lluvias.

A partir de toda esta información registrada en el campo y auxiliados por las fuentes históricas nos podremos adentrar en el problema de la organización social del sitio. La arqueología nos permite obtener evidencias de la estratificación de los mayas; los tipos de casas se ajustan a un patrón diferenciador que debe expresar distinciones importantes en el prestigio de los habitantes. Algunas son residencias reales, mientras que otras pudieron albergar al o los linajes de alto rango. La calidad de la construcción, el planeamiento y los caminos de acceso cuidadosamente pensados, convierten estos complejos arquitectónicos en recintos de élite y, si se llegara a confirmar 
su función de residencias, no sería difícil elaborar el modelo de las características del grupo de parientes que las ocupó.

Sea como fuere, lo innegable es que existe una profunda estratificación, una profunda separación entre nobles y plebeyos. Las fuentes escritas guardan fielmente el recuerdo de esa división, así como las relaciones entre rango y genealogía.

1 Don Tasio desde muy joven se inició en los trabajos de arqueología; en un principio acompañó a su padre Don Anastasio Dzib Chablé a diferentes lugares. Fue así como conoció a los primeros arqueólogos de la Institución Carnegie, trabajando con la mayoría de ellos; posteriormente trabajó también con casi todos los arqueólogos mexicanos que se han dedicado a la zona maya.

Inició su trabajo como casi todos, primero siendo peón, después ayudante. de albañil, media cuchara y albañil, para posteriormente ser ayudante de cabo, y cabo. Muchos de los habitantes de Oxkutzcab por tradición dedican buena parte de su vida al trabajo en las ruinas arqueológicas. Al verlos trabajar uno se siente transportado a los tiempos prehispánicos, son hombres capaces, fuertes, con gran amor a sus tradiciones, grandes conocedores de la arqueología, son realmente los sucesores de esa gran cultura cuya sensibilidad impresiona al mundo entero; además son expertos en la exploración y consolidación.

Ellos saben a la perfección abrir caminos en medio de la selva para llegar a cualquier ciudad maya, montar un rústico campamento, hacer la limpieza de las estructuras, hacer la exploración, montar andamios sin nuestra tecnología, consolidar, etc., sufrir alegremente las inclemencias del tiempo: lluvia, calor, frío, escasez, etc.; son hombres realmente admirables.

Ojalá esa tradición del trabajo en ruinas arqueológicas no se pierda y entre los jóvenes de ese asombroso pueblo se inicie un renacer por esos valores de sus antepasados.

A Don Anastasio Dzib May, lo conocí en 1975 y posteriormente en Tulum (1981-82) fue cabo; lo vi trabajar en múltiples ocasiones y resolver problemas de una manera admirable; fue formador de jóvenes albañiles, a los cuales pacientemente dedicaba su tiempo para enseñarles a explorar y consolidar, lo mismo que a levantar un andamio o hacer la imitación de un piso prehispánico; tenía el don de un gran señor, de un Halach Uinic (Láms. 9 y 10).

Como dijimos, él se inicia desde muy joven en los trabajos de arqueología; participa en las exploraciones realizadas en Chichén Itzá por la Institución Carnegie bajo la dirección de S. E. Morley. Posteriormente, trabaja en Dzibilchaltún con W. Andrews IV, y en Uxmal con Ponciano Salazar, todos estos trabajos fueron los primeros en donde participó siendo todavía cabo su padre Don Anastasio Dzib Chablé.

Como cabo, encargado de todos los trabajadores, participa solo, o con su hermano Crescencio y Juan Chablé, en otros muchos sitios siendo los principales: Uxmal, Ëzzná, Palenque, Bonampak, Mulchik, Jaina, Cobá, Can Cun, Kojunlich, Hormiguero, Xpuhil y Tulum, entre otros muchos. Trabaja, como dijimos, con todos los grandes arqueólogos tanto nacionales como extranjeros entre ellos citaremos a S. Morley, E. Thompson, W. Andrews IV, A. Ruz Luhuiller, Ponciano Salazar, Román Piña Chan, Jorge Acosta, R. Pavón Abreu, Héctor Gálvez, César Sáenz, Víctor Segovia, etc.

Siendo Don Tasio miembro del personal del INAH, en los años 70s, tra- 
baja con muchos arqueólogos jóvenes; al verlo trabajar aprendimos mucho sobre los sistemas de exploración y consolidación de los grandes maestros.

Estos son algunos datos de su trabajo anónimo realizado durante largos años en las ciudades mayas; vaya esto como un pequeño reconocimiento a él y todos aquellos trabajadores anónimos que hacen esa labor $\tan$ meritoria. Los datos aquí presentados fueron proporcionados por su hermano Tomás Dzib Tun.

Nace en Oxkutzcab, Yucatán, el 8 de julio de 1921 y se inicia en los trabajos de arqueología a los 16 años en Chichén Itzá, su último trabajo como cabo lo realiza en Tulum (1981-82) y muere en la ciudad de Mérida, Yucatán, el día 23 del mes de julio de 1983.

\section{BIBLIOGRAFIA}

ANDREWS, ANTHONY P.

1976 "El Proyecto Xcaret y reconocimiento de la costa central de Quintana Roo", en: Boletín, Año 4, No. 19, pp. 10-20, Editorial Zamná, Mérida.

Andrews, E. Wyllys, IV y Andrews Anthony P.

1975 "A Preliminary study of the ruins of Xcaret, Quintana Roo, México: with notes on other archaeological remains on the central east coast of the Yucatan Peninsula", Middle American Research Institute, Publ. 40 Tulane University, New Orleans.

Andrews, George F.

1975 Maya cities: Placemaking and urbanization, Civilization of the American Indian Series, Vol. 131, University of Oklahoma Press, Norman.

BAKER, BLEA

1976 "Maya inter-center spatial organization", Paper presented at the 75th annual meeting of the American Anthropological Association, Washington.

Barrera Rubio, Alfredo

1977 "Exploraciones arqueológicas en Tulum, Quintana Roo", Boletín de la Escuela de Ciencias Antropológicas de la Universidad de Yucatán, No. 24, pp. 23-63, Mérida.

1977 Tulum: economía marino-litoral y sus implicaciones sociales, Sociedad Mexicana de Antropología, XV Mesa Redonda, Vol. II, pp. 237-45, México.

Benavides, Antonio

1976 El sistema prehispánico de comunicación terrestre en la región de Cobá, Quintana Roo, y sus implicaciones sociales, Te. sis Profesional, E.N.A.H., México.

1976 Tancah, Quintana Roo. Informe de actividades julio-agosto, 1975. Investigacıones Arqueológicas en el Sureste, Cuadernos de los Centros Regionales, No. 27, pp. 99-108, INAH, México.

Bullard JR., William R.

1954 "Residential property walls at Majapan", Current Reports 3, Vol. I: 36-44, Carnegie Institution of Washington, Dept. of Archaeology, Cambridge, Mass. 
Escalona Ramos, Alberto

1946 "Algunas ruinas prehispánicas en Quintana Roo", Boletin de la Sociedad Mexicana de Geografía y Estadistica, No. 61, No. 3 pp. 513-528, México.

Garza Tarazona, Silvia y Kurjack, Edwards

1980 Atlas Arqueológico del Estado de Yucatán, INAH, México.

GonzÁle: Crespo, Norberto

1979 "Patrón de asentamiento prehispánico en la parte central del bajo Balsas: Un ensayo metodológico", Colección Científica Arqueología, SEP, INAH, México.

González de la Mata, Rocío y Trejo, A. F.

1981 "Playa del Carmen: excavaciones en la costa oriental de Quintana Roo", Memoria del Congreso interno, INAH, México.

Havmand, William $A$.

1966 "Maya settlement patterns: a crystal review", Middle American Research Inst., 26:21-47, New Orleans.

Kurjack, Edward Barna y E. Willys Andrews B.

1976 "Early boundary maintenance in northwest Yucatán, Mexico, American Antiquity, Vol. 41:318-325, Society for American Archaeology, Washington.

1976 "Tancah, Quintana Roo. Informe de actividades julio-agosto, 1975. Investigaciones Arqueológicas en el Sureste", Cuadernor de los Centros Regionales, No. 27, pp. 99-108, INAH, México.

Thompson J. ERrG

1932 A Preliminary Study of the Ruins of Coba Quintana Roo, Mexico, Carnegie Institution of Washington, Pub. 424.

1959 Grandeza y decadencia de los mayas, FCE, México.

UlGer, DAVID

1978 "Muros de delimitación en Chunchucmil", Boletin de la Escuela de Ciencias Antropológicas de la Universidad de Yucatán, año 5, No. 28: 55-62, Mérida, Yucatán.

Verásquez, Ricardo

1975 "Informe de las exploraciones arqueológicas y trabajos de mantenimiento en la zona de Tulum, Quintana Roo, temporada de campo 1975", en: Cuadernos de los Centros, No. 27, pp. 19-8.3, INAH, México.

Wriey Gordon, R.

1974 "The Classic Maya Hiatus: a Rehearsal for the Collapse?" en: Mesoamerican Archaeology, Hammond, Ed. Austin, pp. 417-430. 







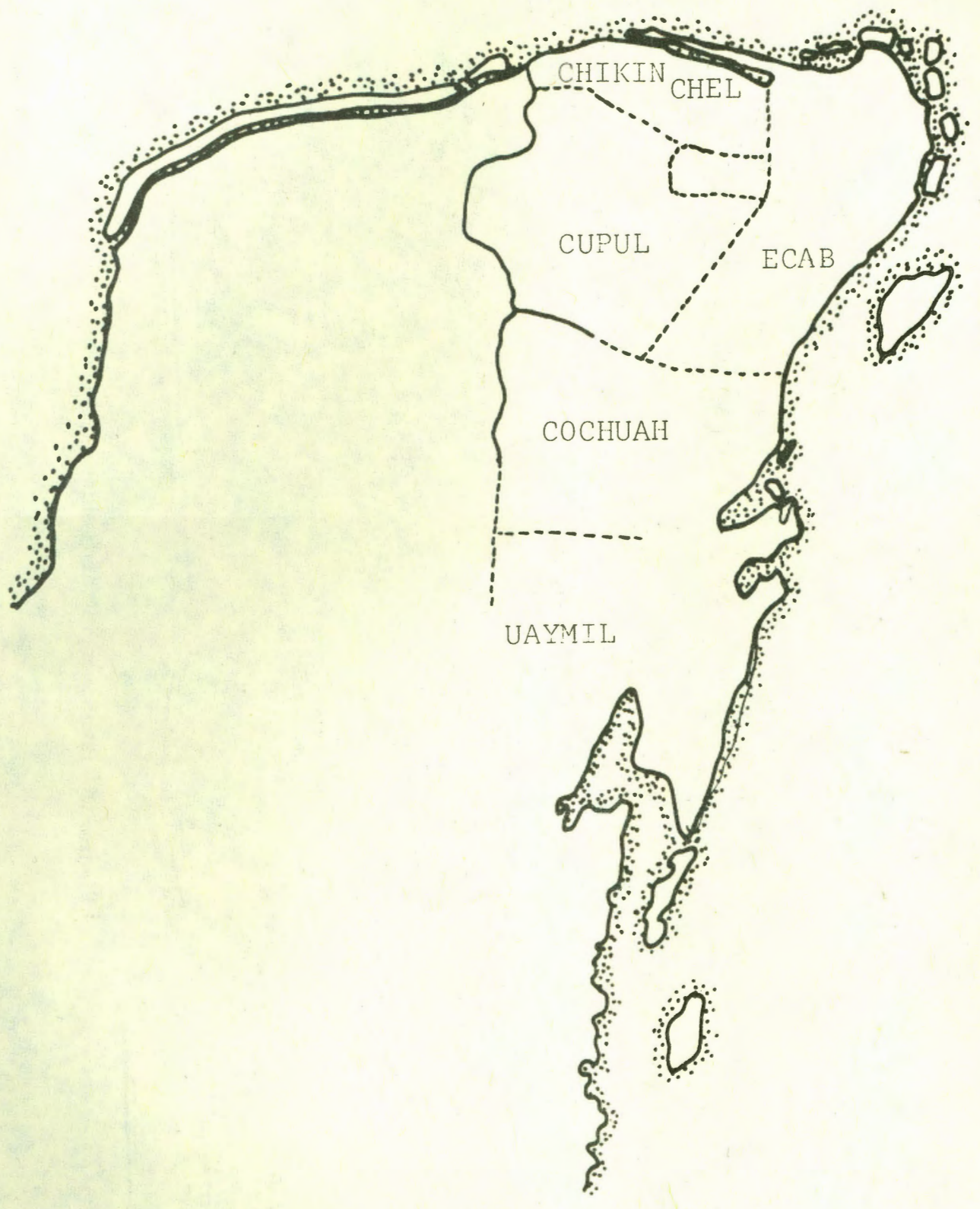

Figura 2: Mapa de Roys prcvincias de Yucatán. 


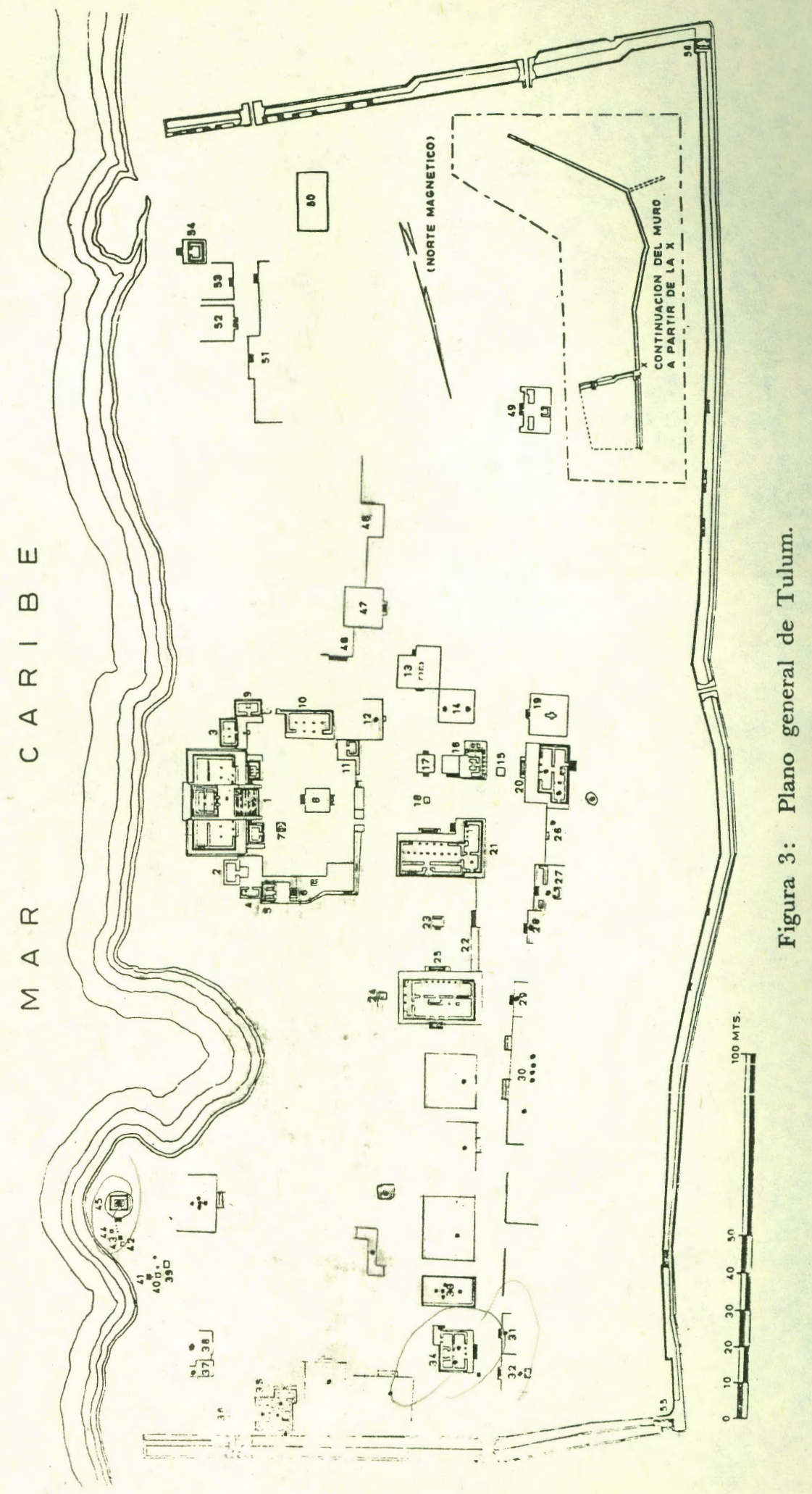




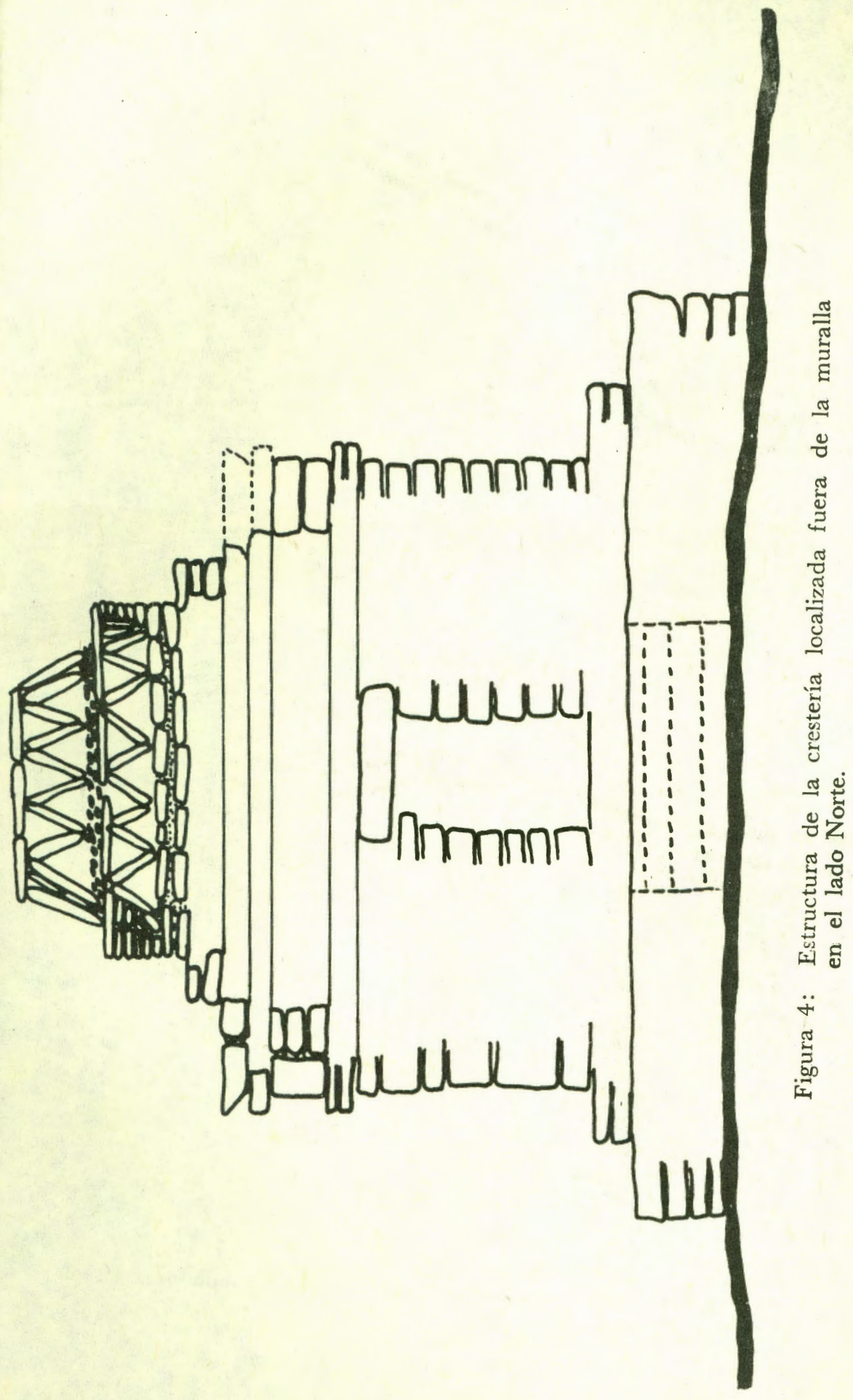




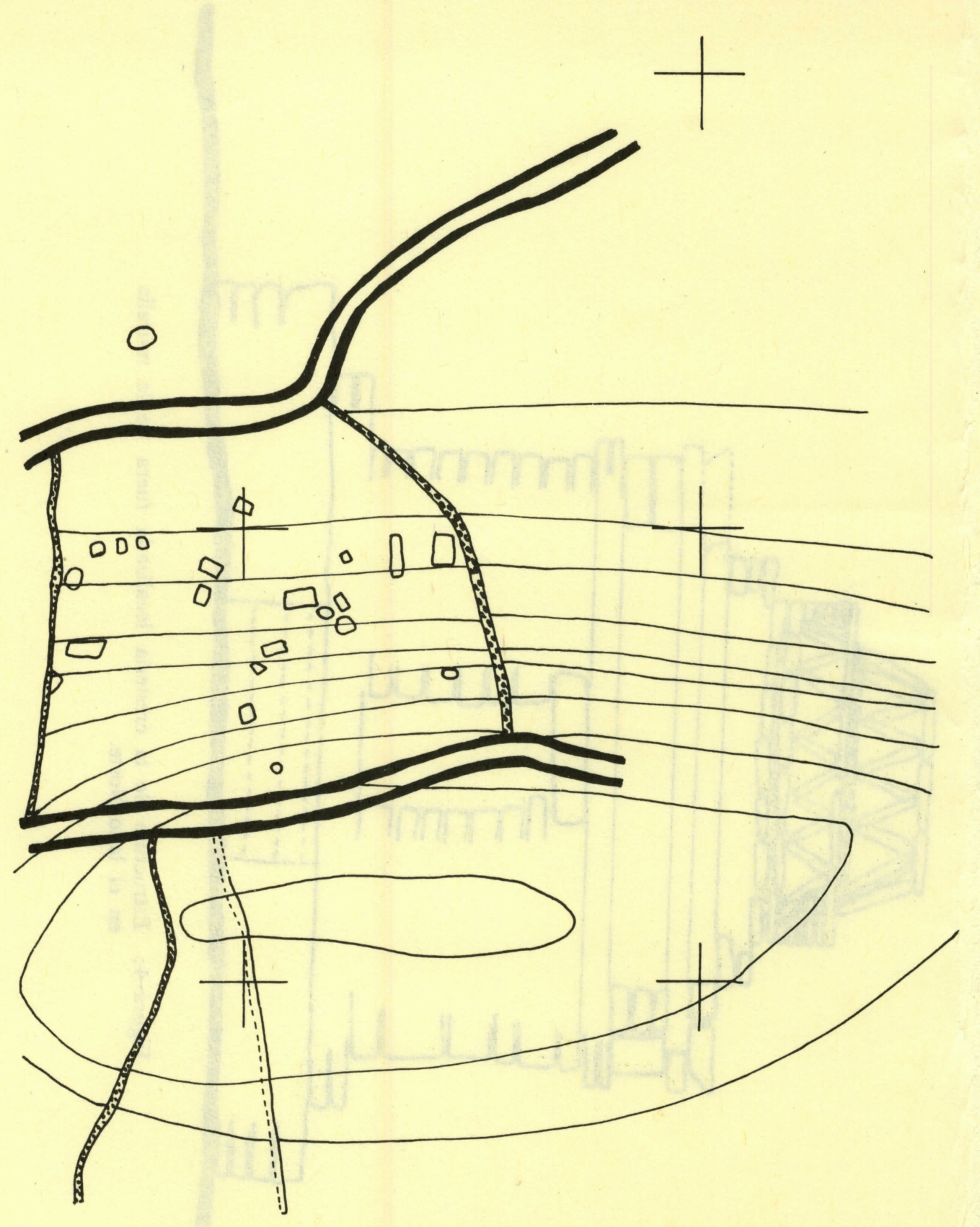

Figura 5: Ejemplo de los caminos formados por 2 andadores en el lado Norte. 

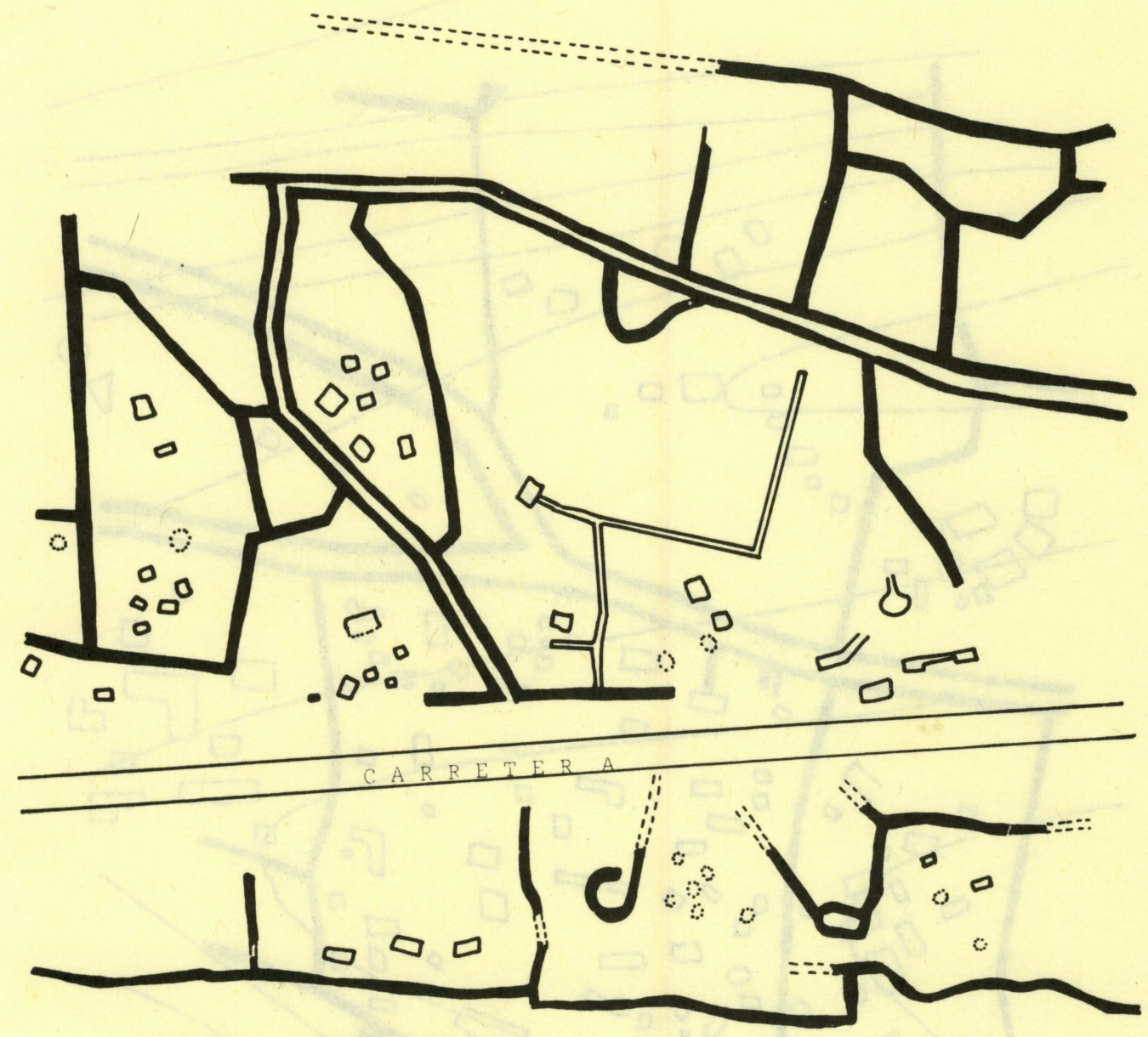
Figura 6: Ejemplo de andadores que comunican lugares cercanos y
posiblemente dividieron zonas. 


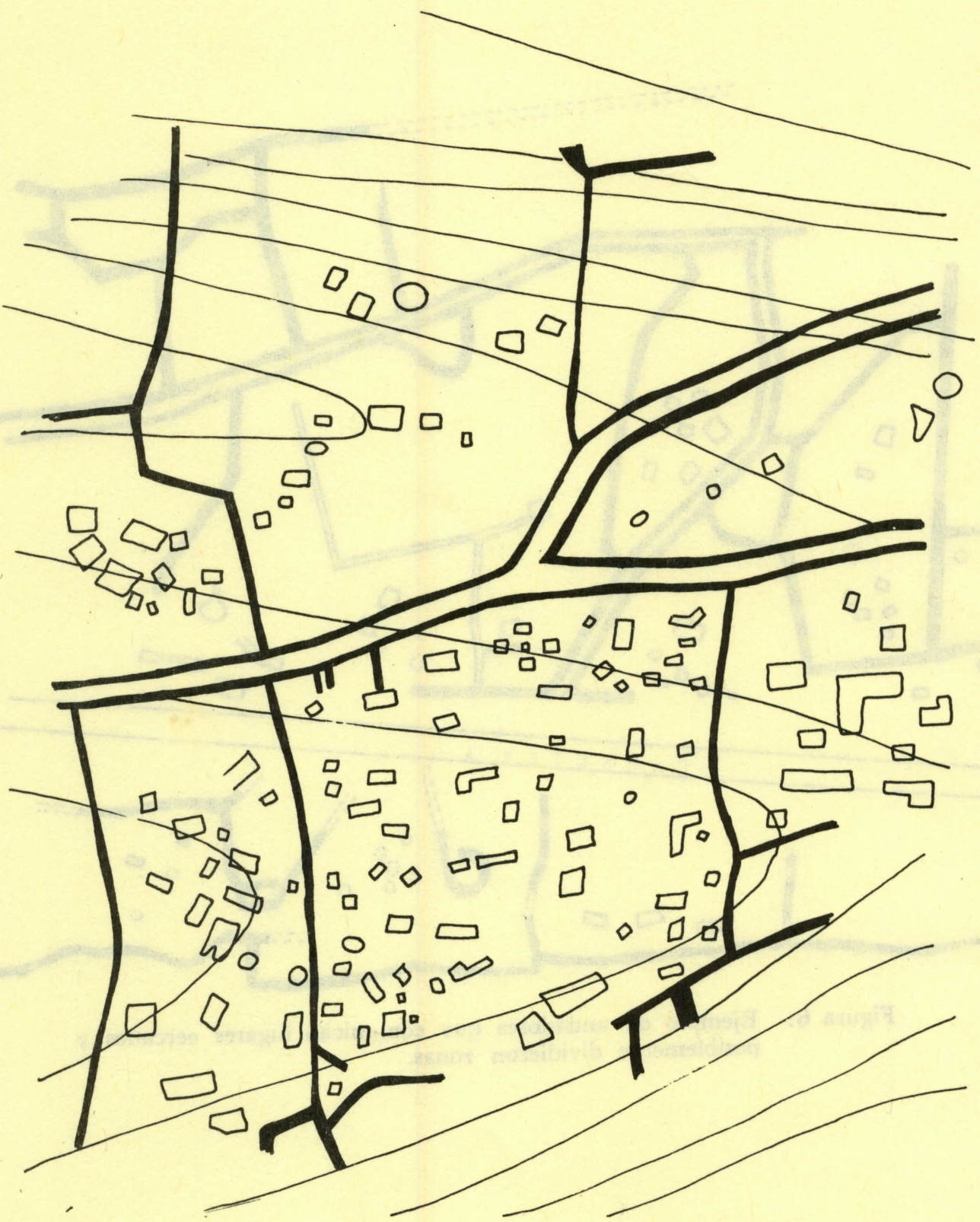

Figura 8: Levantamiento topográfico del lado Norte. 


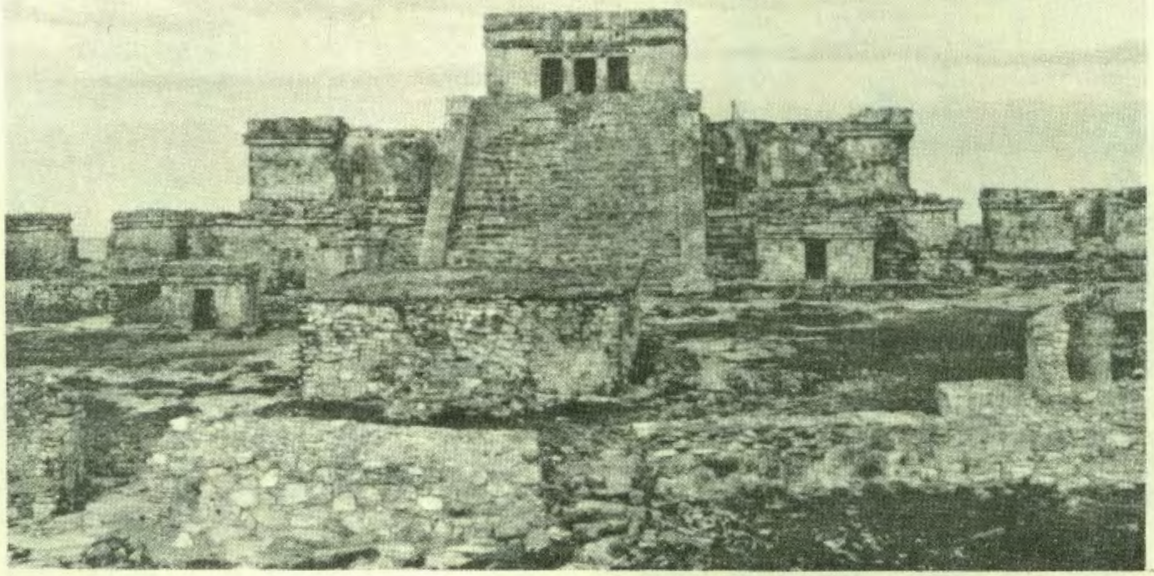

Lámina 1: El castillo.

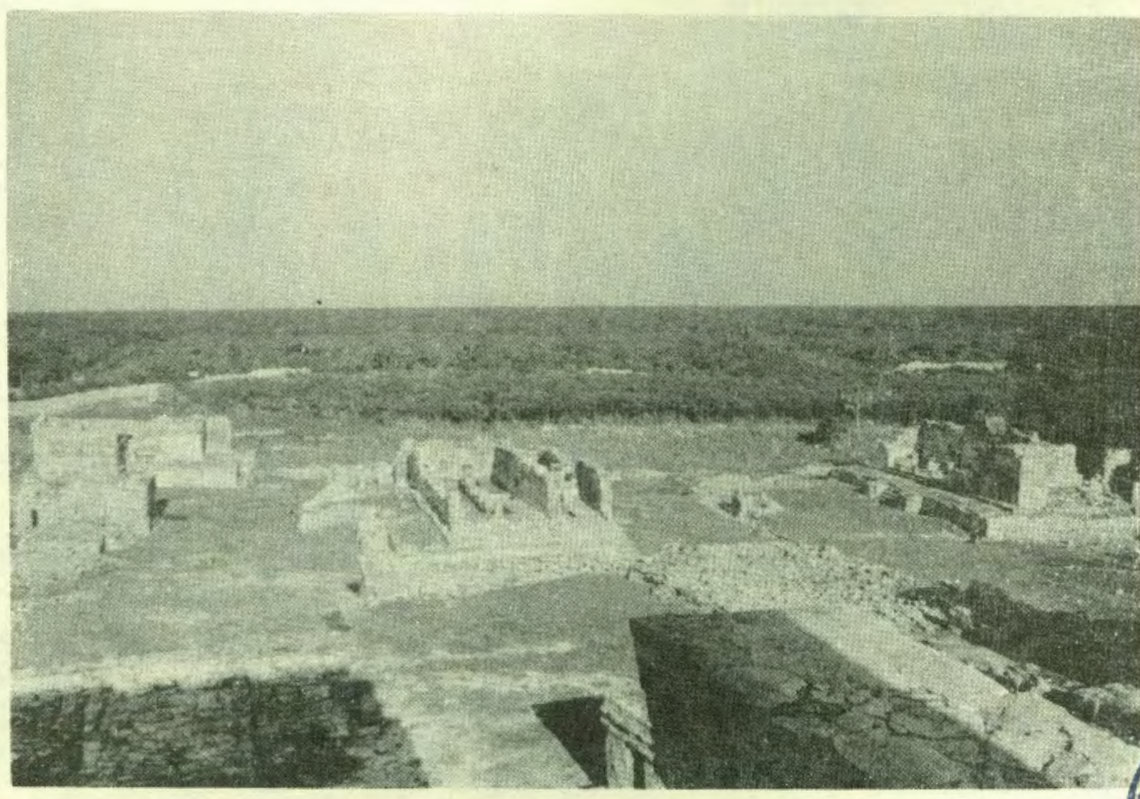

Lámina 2: Vista general de edificios con techo plano.

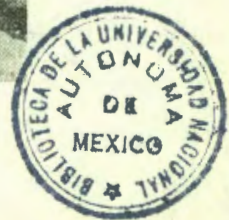




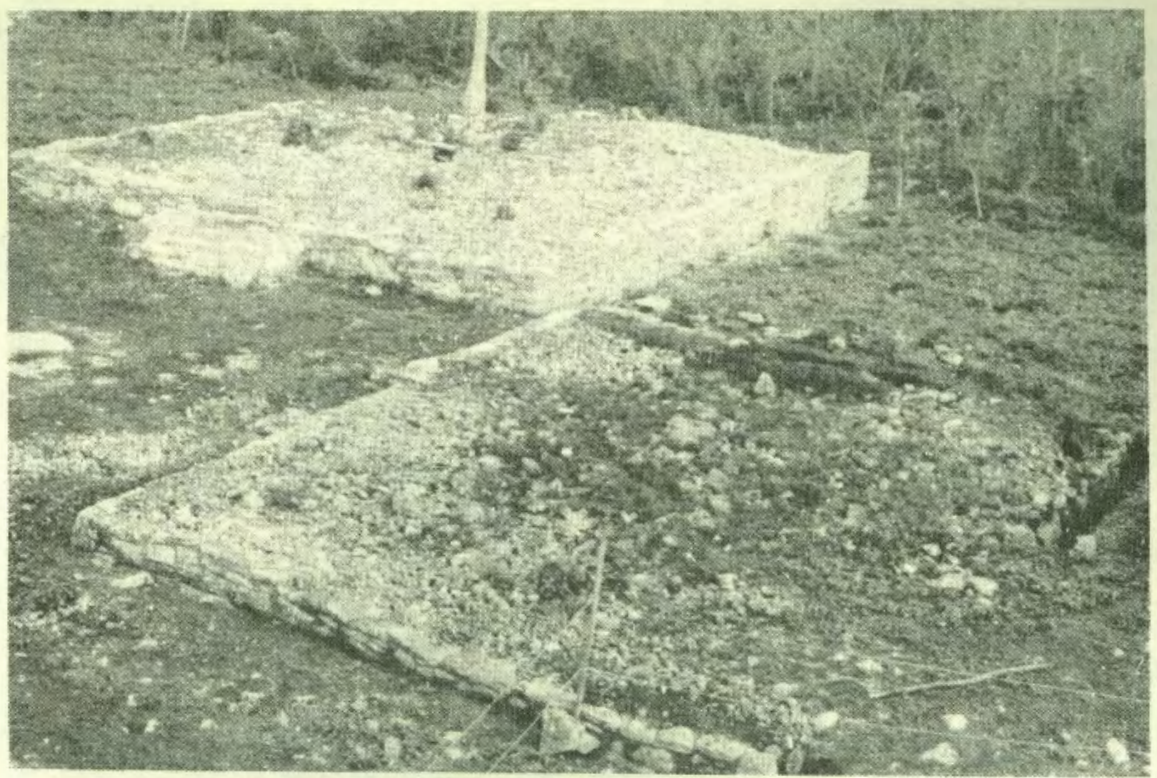

Lámina 3: Construcciones que sostuvieron techos perecederos estructura 37-38.

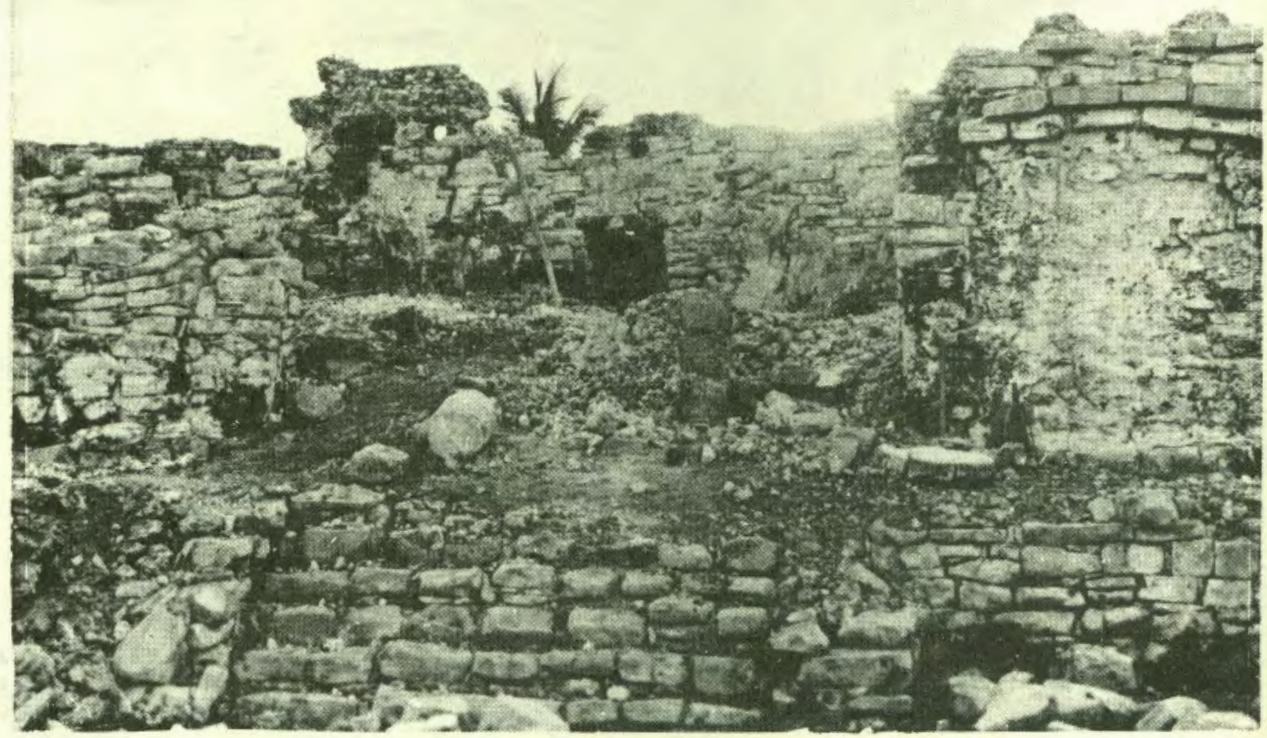

Lámina 4: Construcciones con detalles árquitectónicos (paredes, al. fardas: escaleras, etc.), estructura 33. 


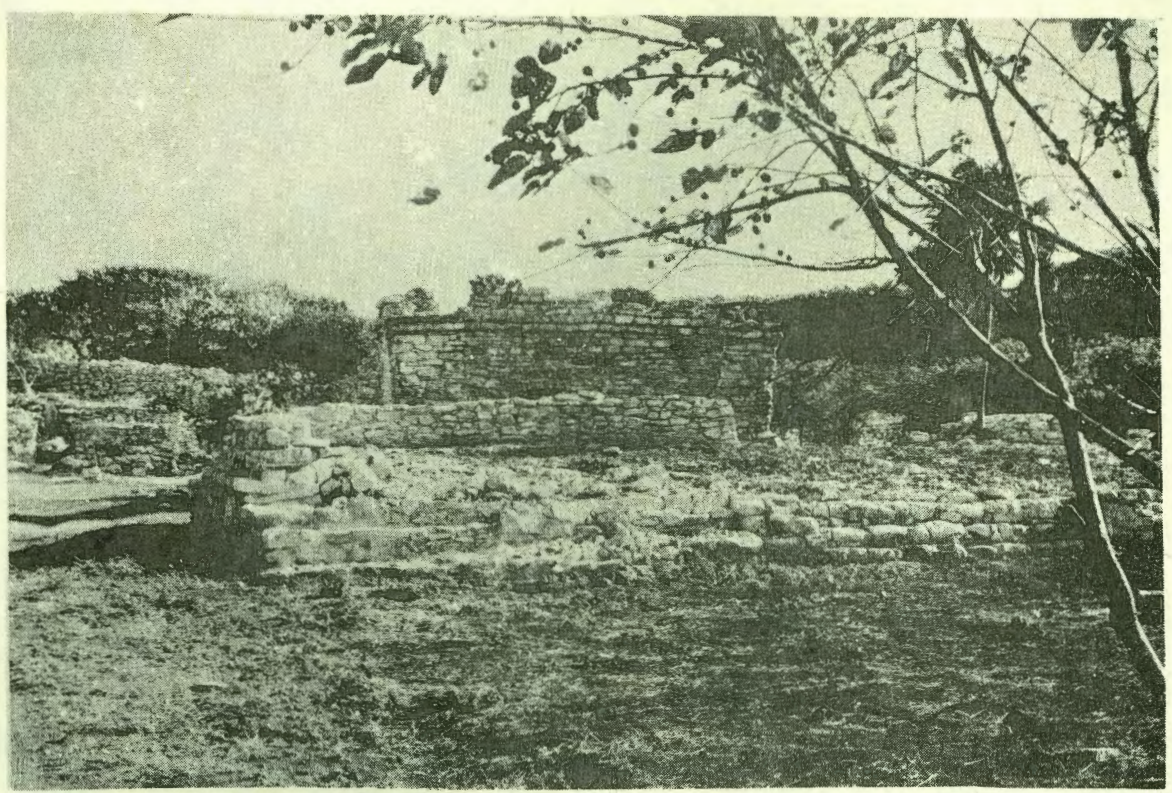

Lámina 5: Plataformas estructura 32-31.

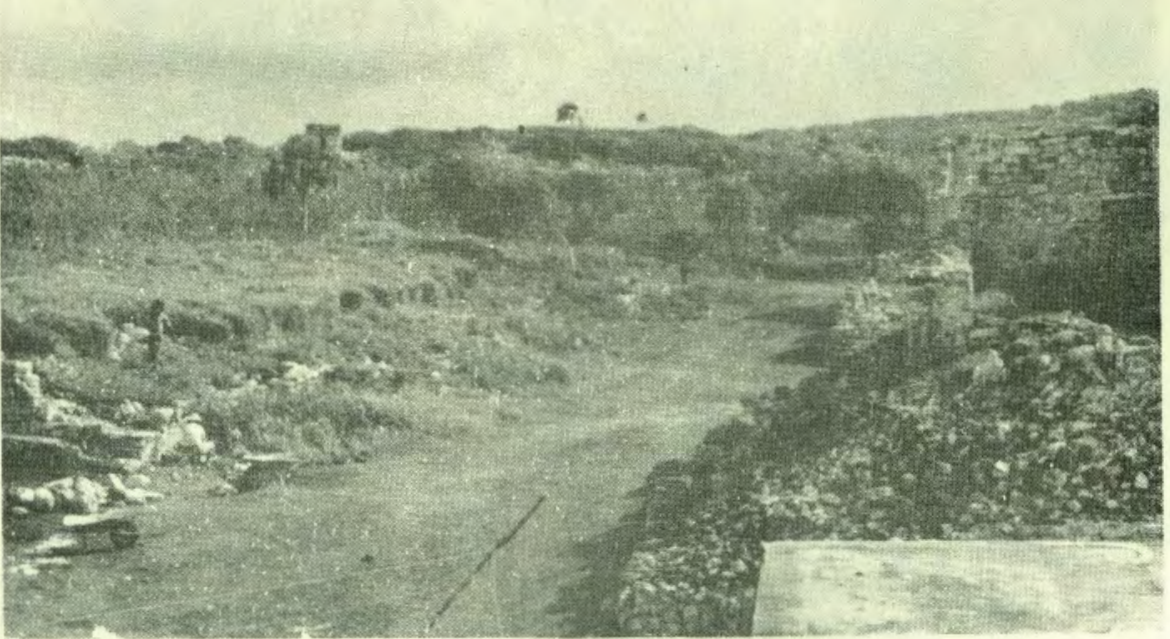

Lámina 6: Ejemplo de caminos formados por plataformas en el interior de la Muralla. 


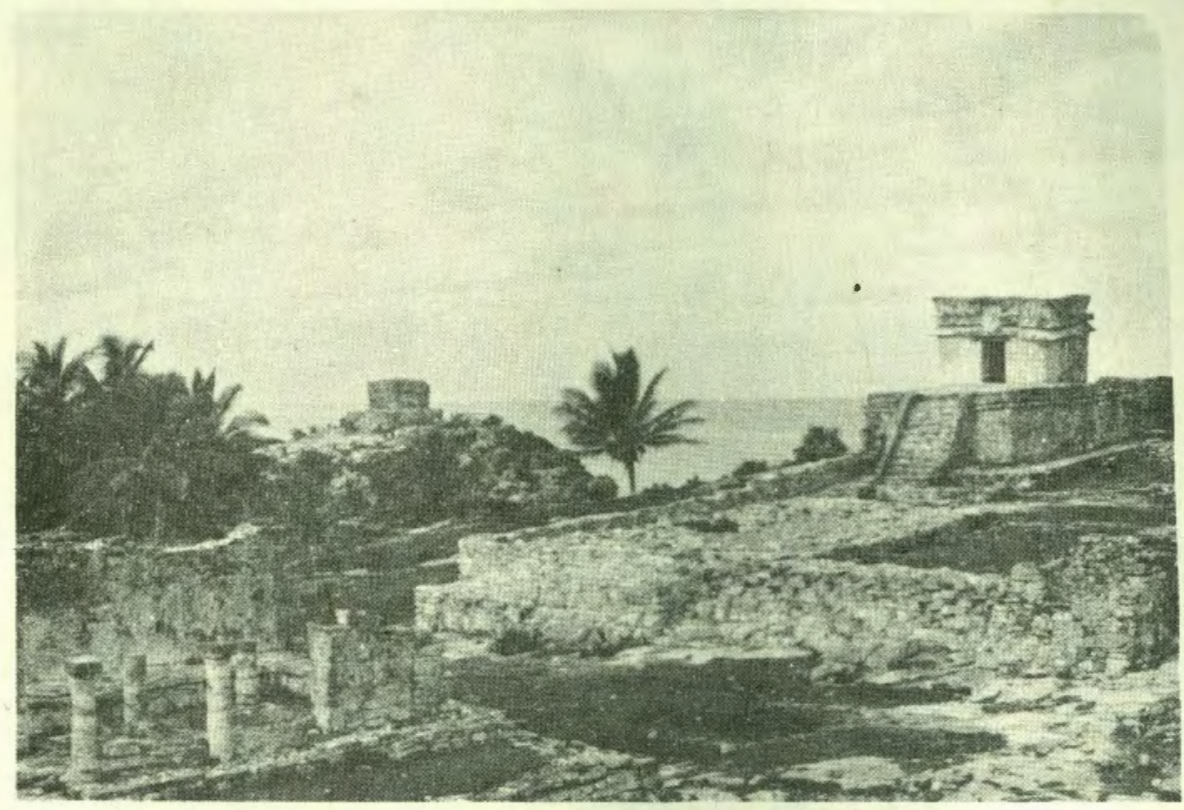

Láminas 7 y 8: Vista general de la Muralla Interior.

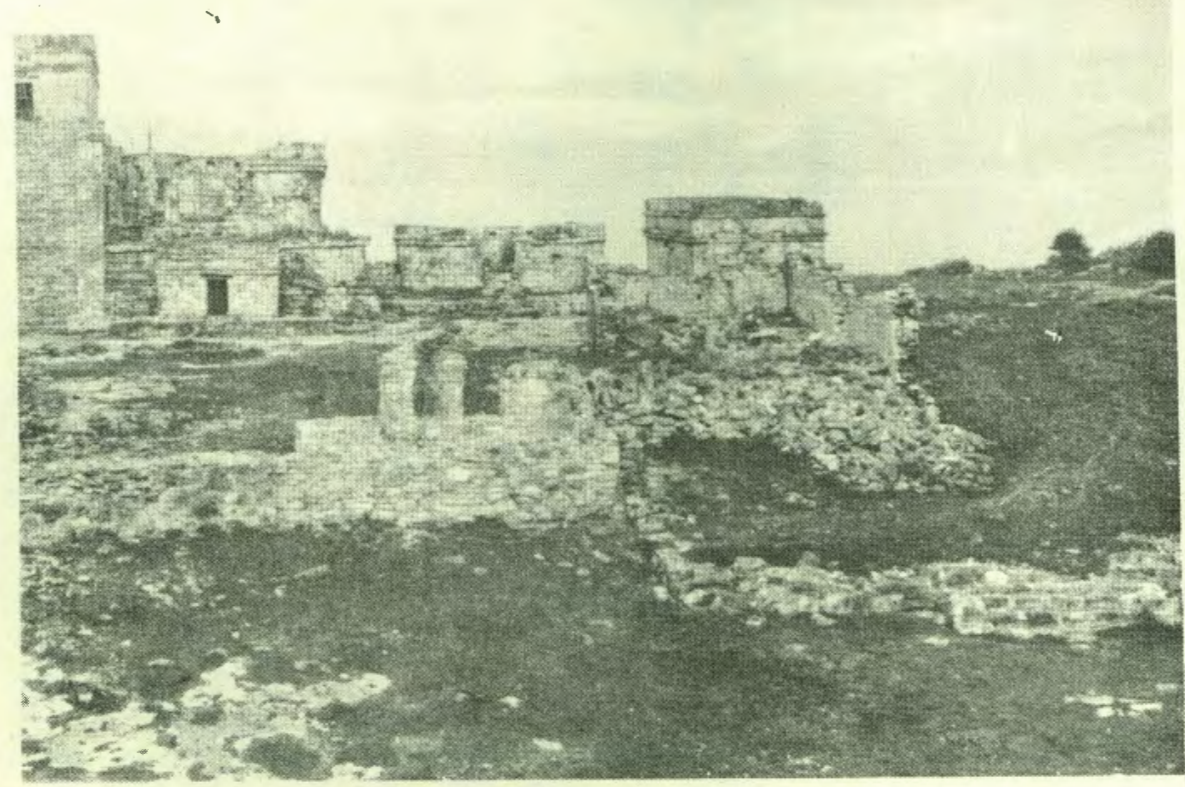




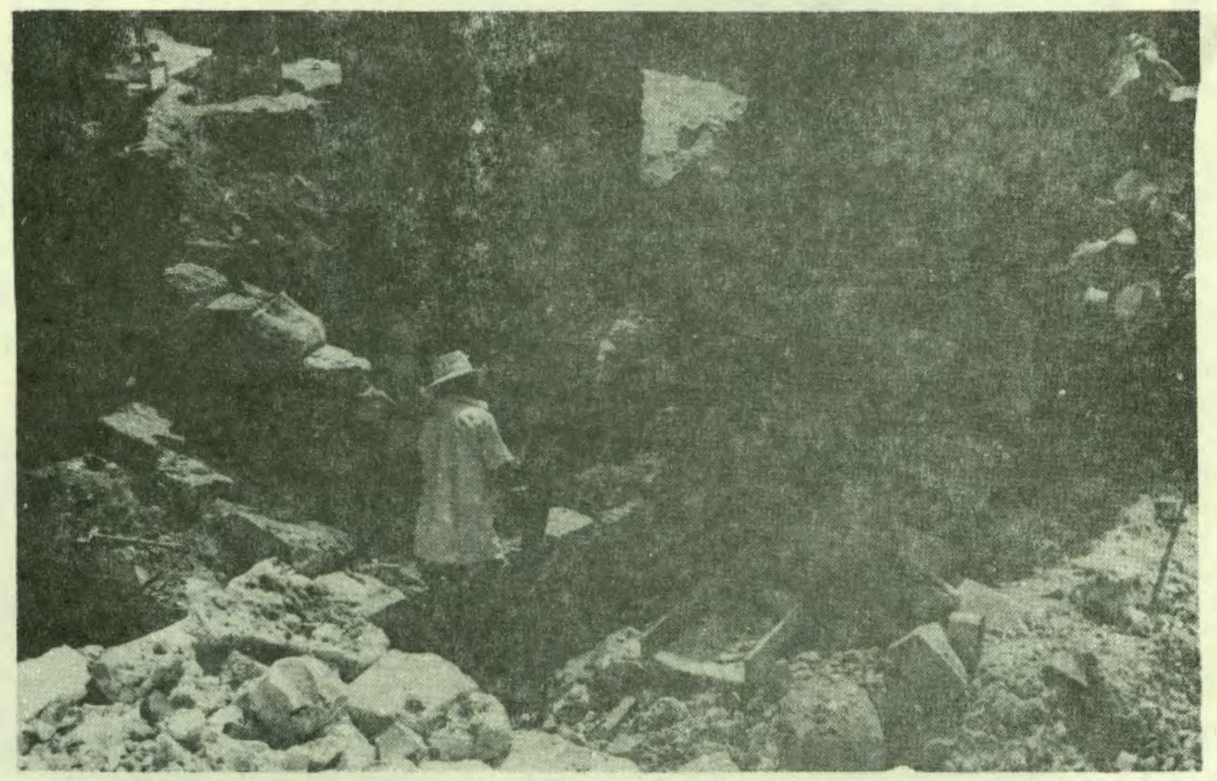

Láminas 9 y 1U: Don Anastasio Dzib May con un grupo de trabajadores en Tulum y en su trabajo diario.

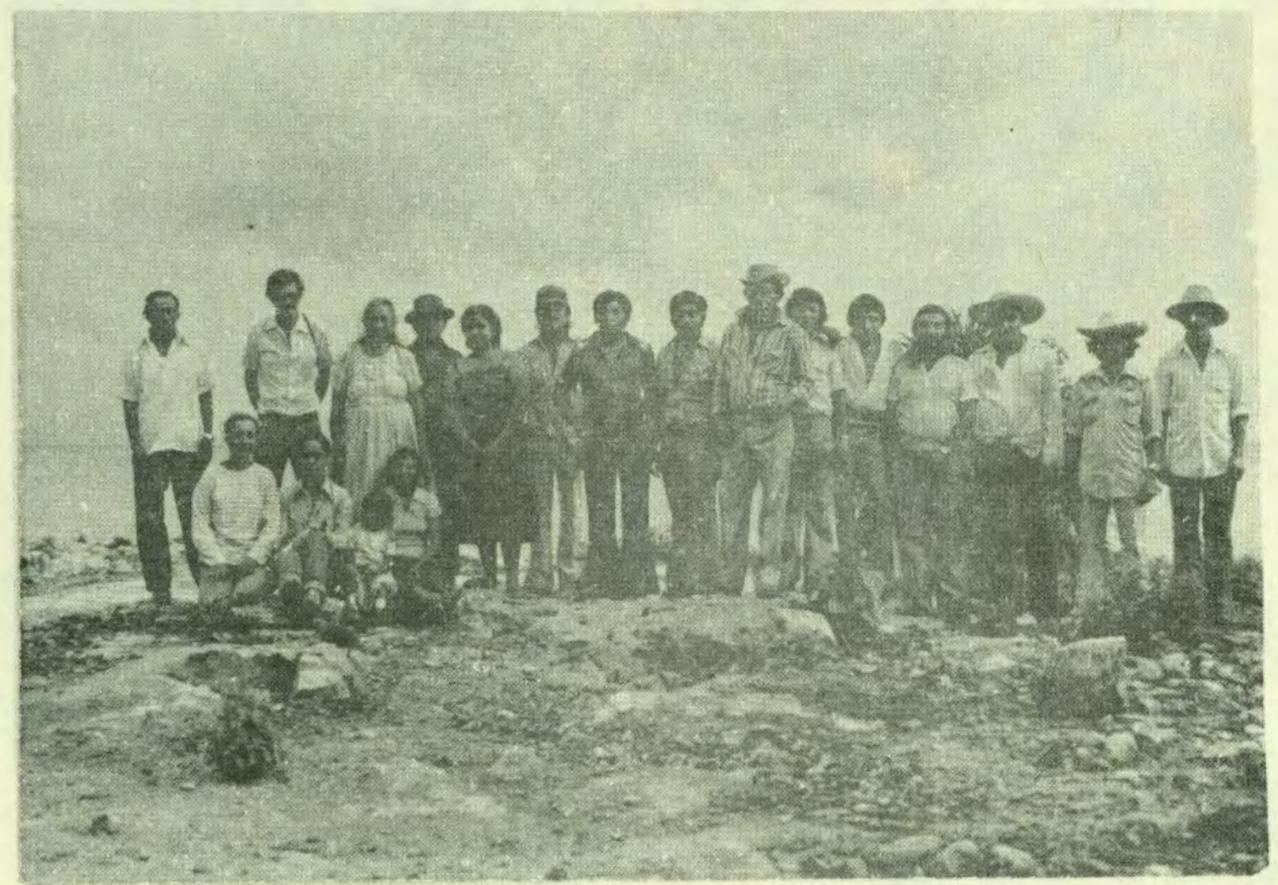

